REFERENCES

Anderson, J. et al. British Medical fournal, 1970, 2, 12.

Christ, O. E., Hertner, W., and Rupp, W. (1969). Hormone Metabolism

and Research, Suppl. No. 1, p. 51.
Hadden, D. R., Bhatia, S. K., Rigas, A. N., Weaver, J. A., and Montgomery, D. A. D. (1969). Hormone Metabolism and Research,

Hadden, D. R., and Weaver, J. A. (1968). Practitioner, 200, 129.
Hebold, G., et al. (1969). Hormone Metabolism and Research, Suppl. No. 1, p. 4.

Hoffman, W. S. (1937). Fournal of Biological Chemistry, 120, 51.

Montgomery, D. A. D., Rastogi, G. K., and Weaver, J. A. (1964). British Medical fournal, 1, 868.

Rigas, A. N., Bittles, A. H., Hadden, D. R., and Montgomery, D. A. D (1968). British Medical Fournal, 4, 25.

Weber, H., et al. (1969). Hormone Metabolism and Research, Suppl. No. 1, p. 1.

\title{
Blood Glucose Variations and Clinical Experience with Glibenclamide in Diabetes Mellitus
}

\author{
D. J. O'SULLIVAN, ${ }^{*}$ M.D., F.R.C.P. ; W. F. CASHMAN, $†$ M.B., B.CH.
}

British Medical fournal, 1970, 2, 572-574

\begin{abstract}
Summary: Thirty patients were treated with glibenclamide for periods up to 16 months. The drug is a potent hypoglycaemic agent, and taken in a single daily dose controls blood glucose levels over a 24-hour period in maturity onset diabetes. A definite dose-effect relaionship exists, and the drug may be used in doses of 5 to $20 \mathrm{mg}$. daily. There were no appreciable side-effects or toxic effects during the period of study.
\end{abstract}

\section{Introduction}

Glibenclamide (Daonil; N-(4-[ $\beta$-(2-methoxy-5-chlorobenzamido) ethyl] benzosulphonyl)- $\mathrm{N}^{\prime}$-cyclohexylurea) is a new active hypoglycaemic sulphonamide, one of many synthetic compounds recently studied in an attempt to produce a hypoglycaemic drug with a more potent and prolonged action. Pharmacological studies have already been published (Aumüller et al., 1966) and clinical trials recently completed are being published (Burns, 1969). This report is chiefly concerned with the acute effects of the drug over 24-hour periods in diabetic patients, and with its value as a hypoglycaemic agent in clinical practice.

\section{Patients and Methods}

Thirty patients (16 women and 14 men) were studied over a 15 -month period. Twenty-eight were more than 40 years old. In 14 the diabetes was recently diagnosed, and no previous therapy had been given. In 14 others control of the diabetes was regarded as unsatisfactory with other oral hypoglycaemic drugs. A further two patients were reasonably controlled on insulin, but had requested a transfer to an oral hypoglycaemic drug. All patients were initially admitted to hospital and put on a standard diet according to their height and weight. After two days on diet alone blood glucose levels were estimated at eight set periods over the 24 hours (fasting, one and two hours after each main meal, and at midnight). A 24-hour urinary glucose estimation was also carried out. Blood and urinary glucose was estimated on the autoanalyser, the glucose-oxidase method being used.

On the next day glibenclamide was begun in a dose of either 2.5 or $5 \mathrm{mg}$. daily. Over the next few days blood glucose was estimated eight times daily, the dose of glibenclamide being increased as indicated. When optimal control had been achieved (usually within six days) a further 24-hour urinary glucose estimation was carried out and the patients were allowed home. They were readmitted after one, three, six, and

\footnotetext{
* Professor of Medicine.

$\dagger$ Lately House-Physician.

Department of Medicine, St. Finbarr's Hospital, and University College,
}

nine months, so that profile blood glucose and 24-hour urinary glucose content could be estimated. Where a significant fall in blood glucose occurred, but satisfactory control of diabetes could not be achieved with glibenclamide alone, phenformin was added in a dose of $50 \mathrm{mg}$. once or twice daily. Combined therapy was necessary in 9 of the 30 patients. Haemoglobin, white cell and differential counts, platelet counts, prothrombin estimation, liver function tests, serum cholesterol, blood urea, and serum proteins were estimated before the drug was begun and then weekly for four weeks, and subsequently after three, six and nine months.

\section{Results}

Assessment of the efficacy of the drug was based on the effects it had on the blood sugar and on the 24-hour excretion of glucose. Control of diabetes was regarded as excellent when two-hour postprandial blood glucose levels were $130 \mathrm{mg}$. $/ 100 \mathrm{ml}$. or less, good when 130 to $150 \mathrm{mg}$., fair when 150 to $180 \mathrm{mg}$., and poor when mean postprandial blood sugars were over $180 \mathrm{mg}$. (Müller et al., 1969).

Using these criteria on the 30 patients investigated, control was excellent in 12, good in 8 , fair in 5 , and poor in 5 (Table I). In one of the latter, a patient who had previously been on insulin for several years, the drug had no demonstrable hypoglycaemic effect and was discontinued after one month. Glibenclamide, not unexpectedly, was far more effective in recently diagnosed and previously untreated diabetics than in those in whom other hypoglycaemic agents had been previously tried unsuccessfully.

TABLE I.-Degree of Clinical Control of Diabetes Mellitus with Glibenclamide in Recently Diagnosed Diabetics and in Those Previously Treated by Other Hypoglycaemic Agents

\begin{tabular}{|c|c|c|}
\hline $\begin{array}{c}\text { Postprandial } \\
\text { Blood Sugar Values }\end{array}$ & $\begin{array}{l}\text { New Diabetic } \\
\text { Patients }\end{array}$ & $\begin{array}{c}\text { Patients Previously } \\
\text { Treated }\end{array}$ \\
\hline $\begin{array}{l}130 \mathrm{mg} . / 100 \mathrm{ml} \text {. (excellent control) } \\
130-150 \mathrm{mg} . / 100 \mathrm{ml} \text {. (good control) } \\
150-180 \mathrm{mg} . / 100 \mathrm{ml} \text {. (fair control) } \\
180 \mathrm{mg} . / 100 \mathrm{ml} \text {. (poor control) }\end{array}$ & $\begin{array}{r}10 \\
2 \\
2 \\
0\end{array}$ & $\begin{array}{l}2 \\
6 \\
3 \\
5\end{array}$ \\
\hline
\end{tabular}

Glibenclamide was always given in a single daily dose with breakfast. The blood glucose profiles in the patients when on diet alone and when the optimal dosage of glibenclamide was reached are shown in Fig. 1. It is seen that the drug exerts its hypoglycaemic effects evenly over the 24 hours, and both the midnight and early morning blood glucose levels are strictly comparable to those at other times of the day.

Mean 24-hour glucose levels before treatment was begun and when optimal dosage was reached, are shown in Table II. While the amount of glucose in the urine varied with the 


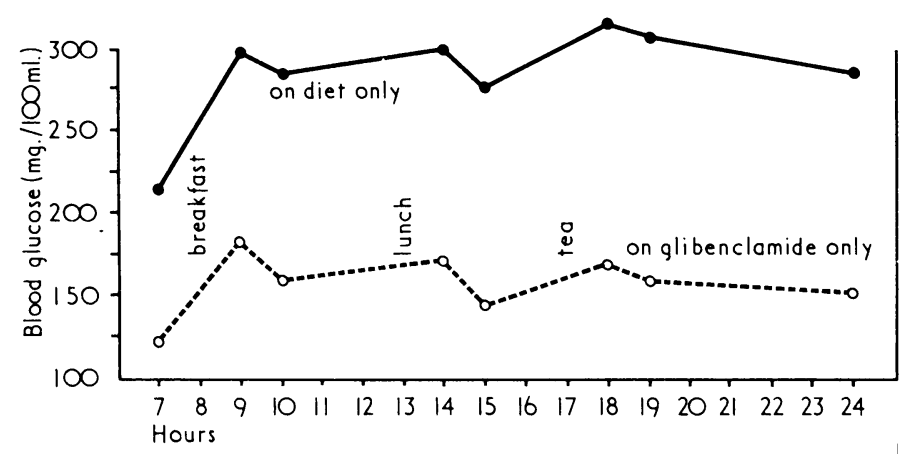

Fig. 1.-Blood glucose profiles throughout the day and following therapy with glibenclamide.

TABLE II.-Mean 24-hour Urinary Glucose Excretion Before and During Glibenclamide Therapy

\begin{tabular}{lll|c|c|c|c|c}
\hline & & & $\begin{array}{c}\text { Excellent } \\
\text { Control }\end{array}$ & $\begin{array}{c}\text { Good } \\
\text { Control }\end{array}$ & $\begin{array}{c}\text { Fair } \\
\text { Control }\end{array}$ & $\begin{array}{c}\text { Poor } \\
\text { Control }\end{array}$ \\
\hline $\begin{array}{lllll}\text { Before therapy } \\
\text { During therapy }\end{array}$ & $\cdots$ & $\cdots$ & $\cdots$ & $\begin{array}{r}59.3 \mathrm{~g} . \\
0.25 \mathrm{gg}\end{array}$ & $\begin{array}{r}54.2 \mathrm{~g} . \\
0.17 \mathrm{~g}\end{array}$ & $\begin{array}{r}35.9 \mathrm{~g} . \\
1.8 \mathrm{~g} .\end{array}$ & $\begin{array}{r}38.1 \mathrm{~g} . \\
7.0 \mathrm{~g} .\end{array}$ \\
\hline
\end{tabular}

degree of control of the diabetes, significant reduction of glucose excretion was noted in all four groups of patients. No significant changes in weight were noted in patients during the trial. Serum cholesterol estimations before and during treatment are available in 28 of the 30 patients. No significant alteration in the serum cholesterol was noted with treatment.

The daily dose of glibenclamide in the present series ranged from 2.5 to $20 \mathrm{mg}$. Nine of the patients required less than $10 \mathrm{mg}$. daily, while 17 required 15 to $20 \mathrm{mg}$. daily. A definite dose-effect relationship was noted. This was found in all patients who responded to the drug; Fig. 2 shows

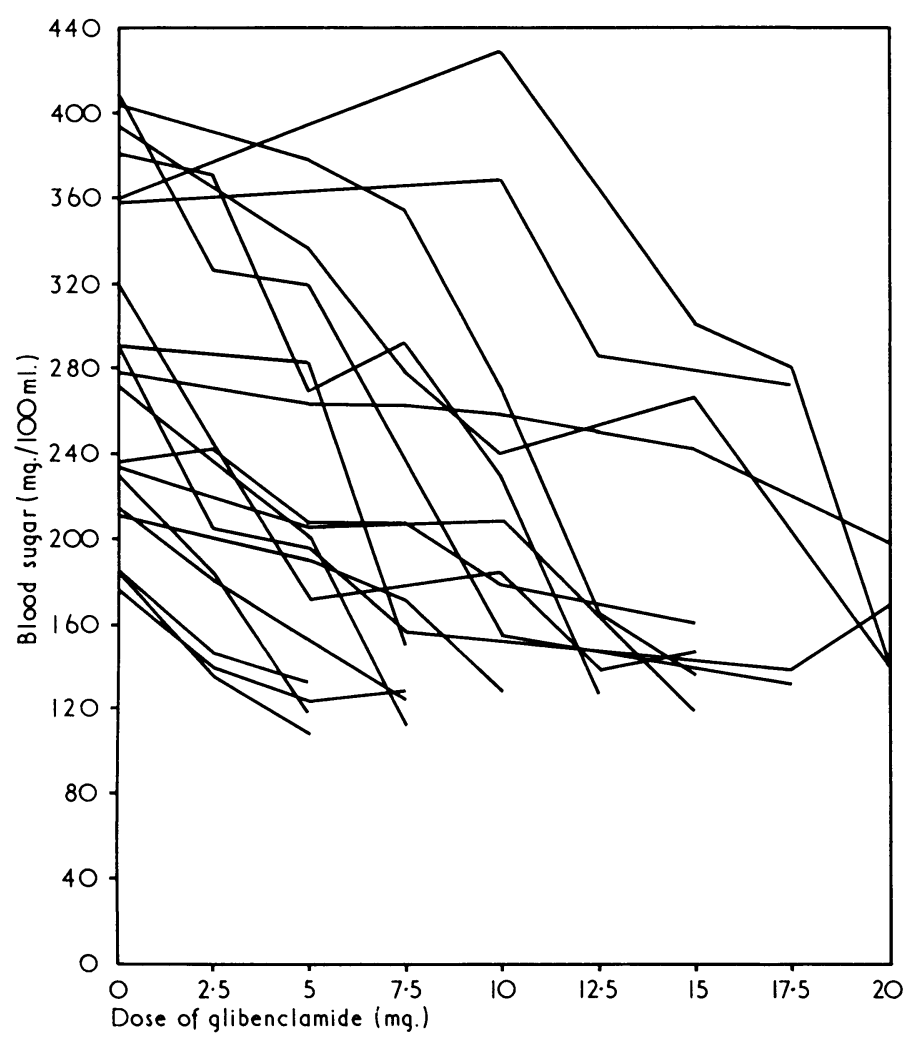

FIG. 2.-Dose-effect relationship with glibenclamide. mean blood sugar levels at different doses of glibenclamide in individual patients who responded to glibenclamide alone. Increasing the daily dose above $20 \mathrm{mg}$. did not result in any further reduction in blood sugar levels.

Two patients had symptoms suggestive of mild hypoglycaemia. This could not be proved as these occurred while the patients were at home. No other side-effects were noted. Toxic effects were remarkably few. One patient had a transient drop in platelets at one clinic visit. They had returned to normal at the next visit. Two patients had transient increases in serum aspartate aminotransferase and serum alanine aminotransferase each at one clinic visit. Both the values had returned to normal at the next visit. No other clinical or biochemical evidence of liver damage was noted. Three patients had unspecified rashes during the course of treatment. All cleared without alteration in the drug dosage. One patient who had troublesome alcohol flushing on chlorpropamide did not experience this when changed to glibenclamide, and alcohol flushing was not noted in any patient in this series.

\section{Discussion}

Glibenclamide has 50 to 600 times the potency of tolbutamide in human subjects (Schmitt et al., 1969). It causes prolonged and persistent stimulation of the beta cells of the pancreas in dogs (Loubatières et al., 1969) and has no effect on the pancreatectomized dog or the alloxan diabetic rabbit (Bänder, 1969). Loubatières et al. (1969) also showed that glibenclamide can potentiate the hypoglycaemic effects of exogenous insulin in the pancreatectomized dog. Kruger (1969) showed an antilipolytic effect four times that of tolbutamide. Hadden et al. (1969) compared blood glucose and immunoreactive insulin levels in small groups of patients receiving tolbutamide, chlorpropamide, and glibenclamide. Blood glucose levels were lower and the insulin-release curve less variable in patients receiving glibenclamide. Apart from the few patients studied, however, those receiving glibenclamide were selected. The insulinogenic index (Seltzer et al., 1967) was nearer normal in the group on glibenclamide than in those receiving the other two sulphonylurea compounds.

The present trial shows that glibenclamide is an effective hypoglycaemic preparation over a 24-hour period when taken in a single morning dose. The variations in blood sugar throughout the 24-hour period are small. If control is shown to be achieved during the day, this can be assumed during the night as well (Fig. 1).

That a definite dose-effect relationship was demonstrated would be considered by some to be a disadvantage (Malins, 1968). With a hypoglycaemic agent such as glibenclamide, it would seem inevitable that a greater dose-effect relationship should exist than with less active drugs. In practice we found that this was no real disadvantage but perhaps led to better and more careful control of diabetes. By starting with a small dose and increasing this until glycosuria was absent or minimal, little trouble was found with hypoglycaemia. It should be emphasized, however, that when the drug is started in a large dose or the daily dose is increased quickly the risk of hypoglycaemia is considerable and has been noted by others (J. Anderson, personal communication, 1969) and ourselves. We would recommend that the drug be started in a dose of $5 \mathrm{mg}$. daily. When the patient is in hospital this can be increased by increments of $5 \mathrm{mg}$. daily, but outpatients should have their dose increased by weekly increments of $5 \mathrm{mg}$. until the diabetes is controlled or a maximal dose of $20 \mathrm{mg}$. daily is attained. Increasing the daily dose beyond this level is of little value. 
Tolerance of the drug was excellent in the present series. Minor gastrointestinal disturbances have been reported elsewhere (Burns, 1969) but were not enoountered by us. Toxic effects were also slight and transient. The potent hypoglycaemic effect of the drug, its prolonged action and relative freedom from toxicity, together with the wide dose range, make it an interesting and useful addition to the hypoglycaemic sulphonylureas.

We are grateful to the sister and staff of the department of medicine, and to the biochemistry department, St. Finbarr's Hospital, for their assistance with the project. Daonil (glibenclamide) tablets were supplied by Hoechst Pharmaceuticals.
REFERENCES

Aumüller, W., et al. (1966). Arzneimittel-Forschung, 16, 1640

Bänder, A., Pfaff, W., Ritter, K., Wohlfahrt, A., and Schmidt, F. H (1969). Proceedings of Tegernsee Conference, p. 21.

Burns, F. H. (1969). Medical fournal of Australia, 2, 436.

Hadden, D. R., Bhatia, S. K., Rigas, A., Weaver, J. A., and Mont gomery, D. A. D. (1969). Hormone and Metabolic Research, Suppl., vol. 1, p. 77 .

Kruger, F. A. (1969). Proceedings of Tegernsee Conference, p. 41.

Loubatières, A., Mariani, M. M., Ribes, G., de Malbosc, H., and Chapal, J.' (1969). Diabetologica, 5, 1.

Malins, J. (1968). Clinical Diabetes Mellitus, p. 367. London, Eyre and Spottiswoode.

Müller, R., Bauer, C., Schröder, R., and Saito, S. (1969). Hormone and Metabolic Research, Suppl., vol. 1 , p. 88 .

Schmitt, H., Höhler, H., Daweke, H., and Jahnke, K. (1969). Deutsche medizinsche Wochenschrift, 94, 824.

Seltzer, Ii. S., Allen, E. W., Herron, A. L., jun., and Brennan, M. T. (1967). Fournal of Clinical Investigation, 46, 323.

\title{
Trickle Arteriography: Demonstration of Thrombi in the Origin of the Internal Carotid Artery.
}

\author{
A. E. HUGH, ${ }^{*}$ M.B. F.R.C.P.ED., F.F.R.
}

\begin{abstract}
Ummary: Thrombi developing within the origin of the

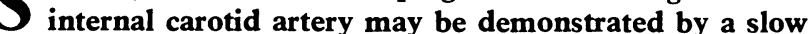
trickle injection of highly concentrated contrast medium, which lingers in pools around the thrombus on the dependent wall of the vessel. With this technique thrombi have been detected which could not be visualized on conventional arteriography because they were obscured by the density of the vascular shadow produced by the forceful injection usually employed in carotid angiography. In addition, trickle arteriography is useful for assessing the position and extent of atheromatous plaques and the contrast stasis associated with them.
\end{abstract}

\section{Introduction}

The value of arteriography in the demonstration of vascular abnormalities has been firmly established for some time, especially where narrowing of the lumen of the vessel is associated with signs and symptoms of ischaemia in the affected part. More recently, attention has been drawn to two particular aspects of arterial disease. One is the pronounced reduction of arterial lumen which must occur before flow through the artery is reduced (Brice, Dowsett, and Lowe, 1964); the other is the association between blockage of small vessels (due to "micro-embolization") and the presence of an atheromatous protrusion into the main artery of supply some way up-stream. The latter association has become increasingly recognized since the direct observation by Ross Russell (1961) and others of retinal emboli in a patient with carotid stenosis, and the clinical manifestations of recurrent small cerebral emboli are now widely recognized. Angiographyboth by direct puncture of the common carotid artery and arch aortography-is commonly used in such patients. Though the work of Brice et al. explains the comparatively low incidence of gross arterial impairment found in these patients, there are a number in whom the clinical evidence of ischaemia leads to the expectation of much grosser arterial disease than is subsequently displayed by conventional carotid or arch arteriography (Marshall, 1964; Sutton and Davies, 1966). * Consultant Radiologist, North Staffordshire Hospital Centre, Stoke-
on-Trent.
Reappraisal of the technique used in carotid arteriography suggests that some information about the vessel wall is concealed by the quantity and concentration of the contrast medium used for the procedure. Normally examination of the vessel in the neck is combined with that of the intracranial vessels, and appropriate amounts and concentrations of medium are injected to fill the latter vessels. Whereas the grosser atheromatous impairments of the carotid arteries are well shown in this way the technique has recently been refined so that lesser abnormalities of these vessels can be demonstrated. In addition to directing the $x$-ray beam in such a way as to open out the carotid bifurcation, taking anteroposterior and oblique views of the neck as necessary, alterations in the amount of contrast medium and mode of injection have been carried out in a deliberate attemnt to delineate the wall of the vessel rather than the rapidly flowing blood within it. One outcome of this is the "trickle" arteriogram, and the procedure and its indications are described below.

\section{Procedure}

Conventional arteriography is first carried out, separate injections of $10 \mathrm{ml}$. of $60 \%$ Urografin being used for the production of the anteroposterior and lateral films. The examination is carried out on a skull table, either with a general anaesthetic or with neuroleptanalgesia, droperidol and Operidine (phenoperidine hydrochloride) being used, and the films are processed in the 90 -second machine so that dry films are available for scrutiny almost immediately. A disposable needle-connexion set is used (18 gauge) and the artery is transfixed as low in the neck as possible. A definite "click" is felt as the needle-tip is withdrawn into the lumen of the artery, and unless this is felt injections are not carried out. Introduced in this way the needle usually makes an angle of about $70^{\circ}$ with the line of the vessel, so that it points at the back wall of the artery rather than along its axis. The lateral series of films is timed to begin slightly before the end of the contrast injection, so that the vessel in the neck is displayed from the needle upward; particular care is taken to display as much of the neck on the film as possible. The anteroposterior film series is started just after the end of the injection, the carotid vessels in the neck not being visible with the $20^{\circ}$ projection employed. 